Thermal-Structural Analysis of the MacArthur Maze Freeway Collapse

C. R. Noble, A. P. Wemhoff, L. D. McMichael

February 27, 2008

ASME 2008 Summer Heat Transfer Conference Jacksonville, FL, United States August 10, 2008 through August 14, 2008 
This document was prepared as an account of work sponsored by an agency of the United States government. Neither the United States government nor Lawrence Livermore National Security, LLC, nor any of their employees makes any warranty, expressed or implied, or assumes any legal liability or responsibility for the accuracy, completeness, or usefulness of any information, apparatus, product, or process disclosed, or represents that its use would not infringe privately owned rights. Reference herein to any specific commercial product, process, or service by trade name, trademark, manufacturer, or otherwise does not necessarily constitute or imply its endorsement, recommendation, or favoring by the United States government or Lawrence Livermore National Security, LLC. The views and opinions of authors expressed herein do not necessarily state or reflect those of the United States government or Lawrence Livermore National Security, LLC, and shall not be used for advertising or product endorsement purposes. 


\title{
HT2008-56109
}

\section{THERMAL-STRUCTURAL ANALYSIS OF THE MACARTHUR MAZE FREEWAY COLLAPSE}

\author{
Charles R. Noble, Aaron P. Wemhoff, Larry D. McMichael \\ Engineering Technologies Division \\ Lawrence Livermore National Laboratory \\ Livermore, California 94550 \\ Email: noble9@IInl.gov
}

\section{ABSTRACT}

At approximately 3:41 AM on the morning of April 29, 2007, a tractor-trailer rig carrying 8,600 gallons $\left(32.6 \mathrm{~m}^{3}\right)$ of fuel overturned on Interstate 880 in Oakland, CA. The resultant fire weakened the surrounding steel superstructure and caused a 50-yard $(45.7 \mathrm{~m})$ long section of the above connecting ramp from Interstate 80 to Interstate 580 to fail in approximately 18 minutes. In this study, we performed a loosely-coupled thermal-structural finite element analysis of the freeway using the LLNL Engineering codes NIKE3D, DYNA3D and TOPAZ3D. First, we applied an implicit structural code to statically initialize the stresses and displacements in the roadway at ambient conditions due to gravity loading. Next, we performed a thermal analysis by approximating the tanker fire as a moving box region of uniform temperature. This approach allowed for feasible calculation of the fire-to-structure radiative view factors and convective heat transport. We used a mass scaling methodology in the thermal analysis to reduce the overall simulation time so an explicit structural analysis could be used, which provided a more computationally efficient simulation of structural failure. Our approach showed structural failure of both spans due to thermal softening under gravity loading at approximately 20 minutes for a fixed fire temperature of $1200^{\circ} \mathrm{C}$ and fixed thermal properties. When temperature-dependent thermal properties were applied, the south and north spans collapsed at approximately $10 \mathrm{~min}$ utes and 16 minutes, respectively. Finally, we performed a preliminary fully-coupled analysis of the system using the new LLNL implicit multi-mechanics code Diablo. Our investigation shows that our approach provides a reasonable first-order analysis of the system, but improved modeling of the transport properties and the girder-box beam connections is required for more accurate predictions.

\section{NOMENCLATURE}

$c_{p}$ Heat capacity

$f_{\text {rad }}$ Radiation view factor

$k$ Thermal conductivity

$L_{D} \quad$ Convective decay length

$L_{x}, L_{y} \quad$ Fire bath width and length

$\mathrm{Nu}$ Nusselt number

$\mathrm{Ra}$ Rayleigh number

$T_{a m b} \quad$ Ambient temperature

$T_{\text {fire }} \quad$ Fire temperature

$T_{\text {gas }}^{*}$ Nondimensionalized convective gas temperature

\section{INTRODUCTION}

A tractor-trailer rig traveling on Interstate 880 in Oakland, CA overturned during the early morning hours on April 29, 2007, spilling 8,600 gallons of fuel. This fuel ignited, causing a fire that sufficiently weakened the surrounding steel superstructure to the point of failure. The available information regarding the incident includes extensive photographic evidence of the structure after the collapse, structural drawings, news articles that included eyewitness accounts, and a video by an East Bay Municipal District (EBMUD) employee at the neighboring sewage treatment plant southwest of the MacArthur Maze (Fig. 1). According to a 


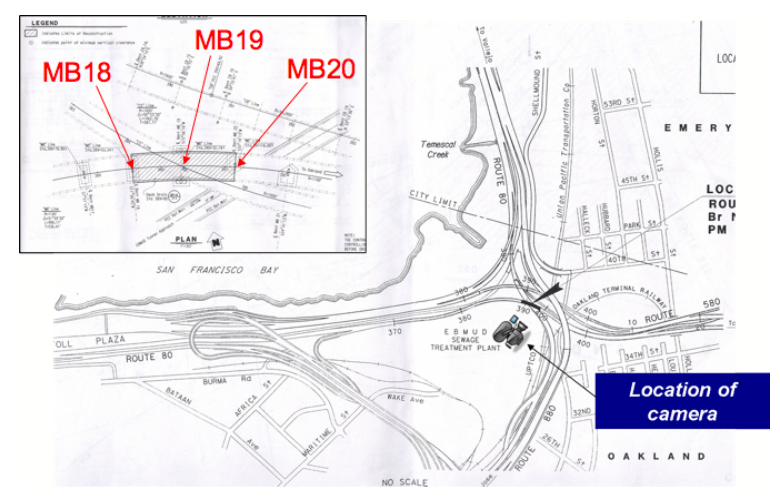

Figure 1. PLAN VIEW OF MACARTHUR MAZE.

San Francisco Chronicle article [1], the gasoline tanker had overturned on a section of I-880 beneath I-580 and caught fire at 3:41 a.m. (Fig. 2). At 3:55 a.m., the I-580 overpass was buckling as firefighters arrived and at 4:02 a.m. the overpass collapsed onto I-880. The Chronicle article also claims that the flames were estimated to be about 3000 degrees, with no units specified (we assumed degrees Fahrenheit, which would correspond to a temperature of 1650 degrees Celsius, which is approximately $500^{\circ} \mathrm{C}$ larger than the transient fire temperature by Buyukozturk and Ulm [2] shown in Fig. 3). The available EBMUD video data showed the fire at 3:37 a.m., which deviates slightly from the stated start time in [1]. At this time, the fire is already in progress, but appears to have recently started due to the limited amount of flames seen in the video at this time. It appears that the fire is initially concentrated under the northern span of the I-580 interchange, which is the span between bents MB18 and MB19. It is interesting to note that at around 9 minutes into the blaze, a significant amount of small "droplets" of burning material is falling from the above superstructure. This could correspond to spalling of thin layers of concrete from the face of the concrete roadway, which is seen when concrete is subjected to very high temperatures [2]. Approximately 16 minutes and 42 seconds into the fire, the south span of the I-580 (between bents MB19 and MB20) collapsed. 1 minute and 22 seconds later, the MB18-19 span collapsed, which means that both spans collapsed within 18 minutes and 4 seconds after commencement of the EBMUD video footage.

The structure of interest is comprised of a $7.75 \mathrm{in} .(19.7 \mathrm{~cm})$ reinforced concrete roadway that is 45 feet $(13.7 \mathrm{~m})$ wide, which sits upon a lattice of steel beams and girders. The minimum clear distance between the I-880 roadway to the I-580 roadway is $15^{\prime}-$ 6" (4.72 m) (Fig. 2). At MB18 and MB20, steel bent caps rest upon a singular steel cased reinforced concrete elliptical column. At MB19, a steel box beam rested on two steel cased reinforced concrete elliptical columns that were placed just outside the I880 roadway below. The box beam sat upon steel reinforced elastomeric bearing pads with no fixed connection between the

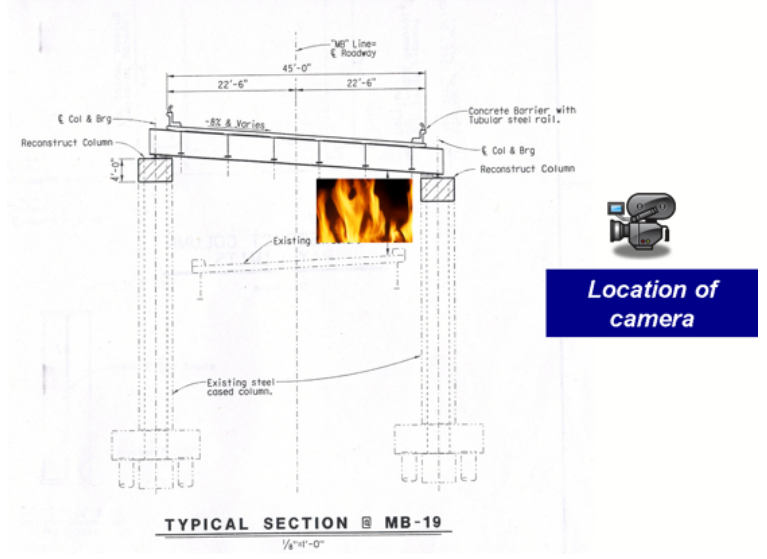

Figure 2. TYPICAL SECTION AT MB19 AND LOCATION OF FIRE AND CAMERA.

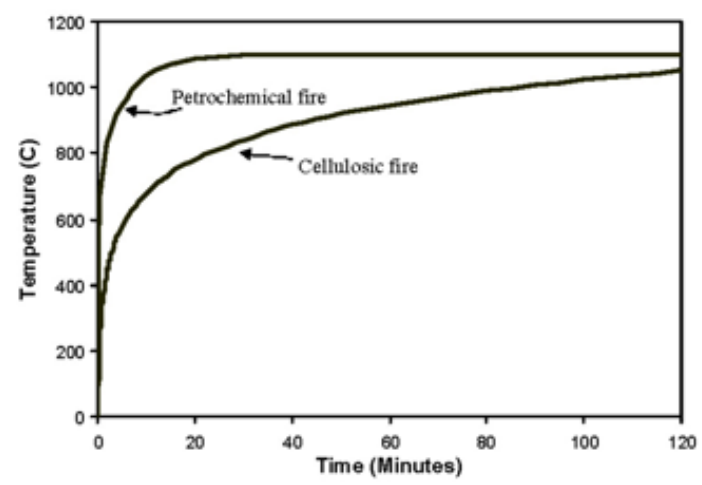

Figure 3. TRANSIENT PETROCHEMICAL FIRE TEMPERATURE FROM [2].

beam and the bearing pads or columns below, which allowed the beam to freely slide along the bearing pads during the collapse. There are six steel girders that span between the bents and steel diaphragms that are placed at third points along the MB18-19 span and at quarter points along the MB19-20 span. The girders also had stiffeners which were placed at equal distances along each span. The MB18-19 span is approximately 77 feet $(23.5 \mathrm{~m})$ in length and the MB19-20 span is approximately 84 feet (25.6 $\mathrm{m}$ ) in length. The girder connections at bents MB18 and MB20 consisted of a reduced and stiffened web section bolted to steel bearing plates at the base of the stiffened web section. The connection at bent MB19 consisted of the girder webs bolted to two steel angle plates with the angle plates bolted to the box beam. The reinforced concrete consisted of reinforcement with a yield strength of $60 \mathrm{ksi}(414 \mathrm{MPa})$ and concrete with a compressive strength of $3.6 \mathrm{ksi}(24.8 \mathrm{MPa})$. The steel girder flanges, girder 
webs, and stiffener plates were fabricated from ASTM A709 Grade 50 steel, and the diaphragms and miscellaneous metals were fabricated from ASTM A709 Grade 36 steel.

\section{COLLAPSE ANALYSIS}

We modeled this thermal-structural problem using four existing LLNL codes in the interest of code verification: NIKE3D [3], DYNA3D/Paradyn [4, 5], TOPAZ3D [6], and Diablo [7]. NIKE3D is a nonlinear implicit three-dimensional finite element code for solid and structural mechanics. DYNA3D and its parallel version, Paradyn, is LLNL's nonlinear explicit threedimensional finite element code for solid and structural mechanics. TOPAZ3D is an implicit three-dimensional finite element heat transfer code and Diablo is a parallel implicit multimechanics code, which essentially combines functionalities from NIKE3D and TOPAZ3D into a coupled parallel format. NIKE3D was used for studying the stresses and deflections of the structure under gravity loads, eigenvalue analysis of the two span section of the I-580 interchange, and for performing scoping calculations on the thermal/structural analysis. An implicit code such as NIKE3D is probably the best finite element platform to perform this type of long time scale thermal/structural analysis, but NIKE3D does not have the capability of modeling material failure using element deletion. This limitation made it difficult for NIKE3D to replicate the span collapse, so Paradyn was also used in order to account for material failure using element deletion criterion. The gravity stresses and deflections were calculated in Paradyn by slowly ramping up gravity with 5\% mass proportional damping turned on during the gravity loading phase. Once the gravity loads were applied, the thermal/structural analysis would commence. The thermal loads were calculated using TOPAZ3D prior to performing the structural analysis. TOPAZ3D exported nodal temperature histories for use in the structural codes, NIKE3D and Paradyn. Diablo is a relatively new finite element code that was used to test the capability of performing a fully-coupled thermal/structural analysis on a parallel platform. One advantage of a fully-coupled approach is the deformed geometry influences how thermal loads are propagated into the structure.

\section{Structural Analysis}

The finite element model consisted of approximately 150,000 8-node hexahedral elements and approximately 226,000 nodes (Figs. 4, 5, 6). The model used three sets of material properties for the analyses and also used contact interfaces between the MB19 box beam and bearing pads. One material was used for the ASTM A709 Grade 50 steel, one for the ASTM A709 Grade 36 steel, and one for the reinforced concrete roadway. A thermo-elastic-plastic model was used for the steel and concrete material models in NIKE3D. A thermo-elastic-plastic model was
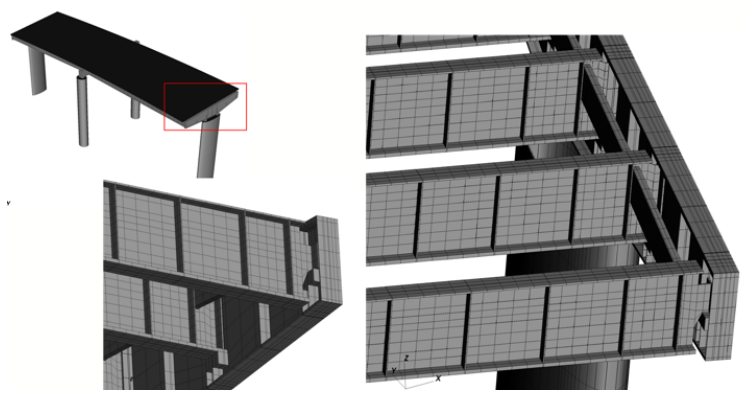

Figure 4. FINITE ELEMENT MODEL CONNECTION DETAIL AT BENT MB20 (SIMILAR TO DETAIL AT BENT MB18).

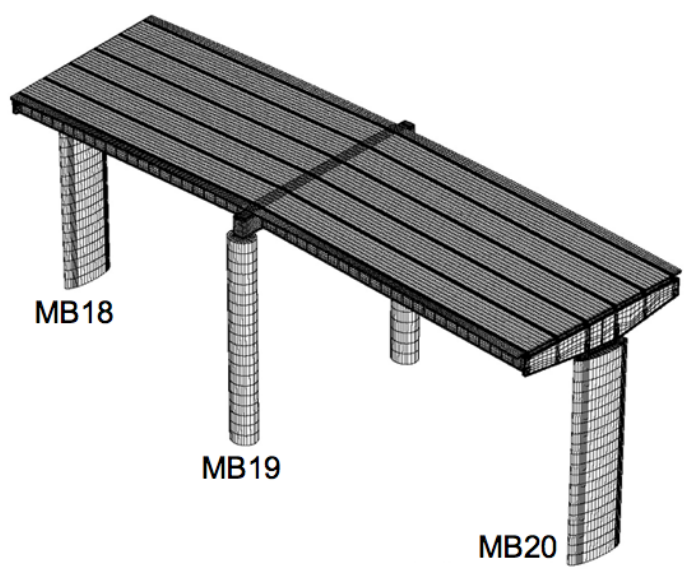

Figure 5. FINITE ELEMENT MODEL OF MB18-20 SPAN OF I-580 MACARTHUR MAZE INTERCHANGE.

used for the steel and the Karagozian \& Case $(\mathrm{K} \& \mathrm{C})$ nonlinear concrete model was used for the concrete roadway in the Paradyn model. For both the NIKE3D and Paradyn models, the reinforcement was not included into the roadway for the purpose of model simplification. In NIKE3D, the yield stress of the concrete was assumed to be only $1000 \mathrm{psi}(6.89 \mathrm{MPa})$ for the thermo-elasticplastic model, with the objective that the roadway would provide mass but not provide much strength to the overall structure. In Paradyn, the compressive strength of the concrete was chosen to be $4 \mathrm{ksi}(27.6 \mathrm{MPa})$, which reflects an increase in the original strength of $3.6 \mathrm{ksi}$ due to concrete aging [8].

For the thermo-elastic-plastic models, eight sets of material properties can be used to define the behavior of the material at different temperatures. All material properties remained the same for every temperature except for the yield strength and elastic modulus. A list of the yield strength and elastic modulus reduction factors for various temperatures are given in [9].

The first set of finite element analyses performed was the gravity initialization in NIKE3D, Paradyn, and Diablo. All three 


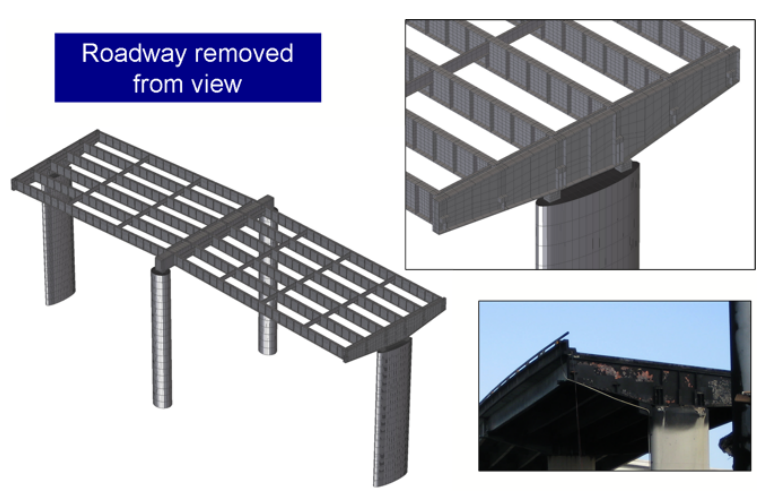

Figure 6. BENT CAP FINITE ELEMENT DETAIL AT BENTS MB18 AND MB20.

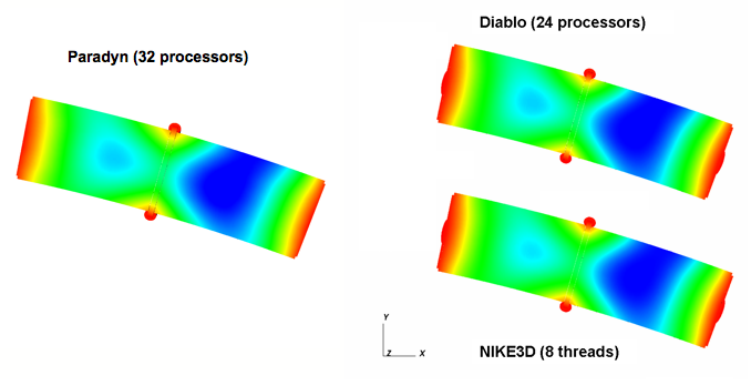

Figure 7. VERTICAL DISPLACEMENT FRINGE PLOTS FROM GRAVITY LOADING. RED AREAS HAVE ZERO DISPLACEMENT, AND BLUE AREAS HAVE 0.5 IN. (1.27 CM) DISPLACEMENT.

finite element codes calculated very similar solutions. A vertical displacement comparison is given in Fig. 7. The red color corresponds to a zero displacement and blue corresponds to 0.5 inches $(1.27 \mathrm{~cm})$ in displacement. Structural drawings from the California Department of Transportation indicated that the maximum calculated vertical displacements of the girders for the MB18-19 and MB19-20 span was 0.375 inches $(0.953 \mathrm{~cm})$ and 0.5 inches $(1.27 \mathrm{~cm})$ respectively, which appear to be in good agreement with the finite element predictions.

Once the gravity initialized state was determined, a NIKE3D eigenvalue analysis was performed on the structure. Figure 8 provides the first five modeshapes of the finite element model. These predicted modeshapes are plausible based on general engineering judgement.

\section{Thermal Analysis}

Modeling of the fire heat transport to the surrounding steel superstructure with limited available resources is a difficult task. Video of the incident demonstrates that the flame pool constantly changed shape and orientation due to changes in wind patterns

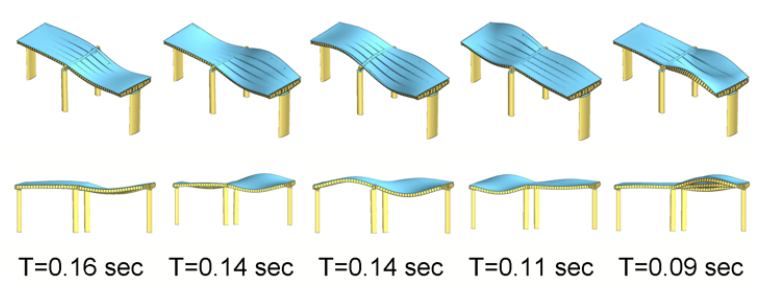

Figure 8. FIRST FIVE MODESHAPES AND CORRESPONDING PERIODS OF THE MACARTHUR MAZE FINITE ELEMENT MODEL.

and confinement due to the failing structure. Therefore, a reasonable first approximation of the fire is to model a moving, transforming region that follows an assumed heat transport methodology between the fire and the surrounding structure. This fire bath contains both convective and radiative transport modes to the solid surfaces of the superstructure that lay within the fire bath. Performing the analysis in this manner allows for simple heat transfer analysis for surfaces immersed in the fire bath.

Determination of the transport between the fire and the structure outside the fire bath is not as straightforward, but fortunately this is not as critical since failure is most likely to occur within the fire bath since that is where the heat transport is greatest. In order to facilitate the calculation of the heat transport to surfaces outside the fire bath but oriented toward the flames, methods were applied that allowed for a smooth transition of maximum heat transport for surfaces within the fire bath out to zero heat transfer at an infinite distance from the fire. The methods, described below, were applied by modifying the source code of the implicit thermal finite element code, TOPAZ3D [6].

Radiative Transport. The most direct means to model the reduction in heat transfer between the fire and surfaces outside the fire bath with respect to distance is to implement view factor relations. The only feasible means to use analytical relations to calculate the view factor is to approximate the fire bath as a rectangular box whose height spans between the two road structures. For the mesh used in this study, the size of a finite element facet is much smaller than the size of the side of this boxed region, so the differential surface-finite surface view factor relations can be used where the differential surface is normal to the finite rectangle aligned with rectangle's corner (Fig. 9, Case A) [10]:

$$
f_{\text {rad }}=\frac{1}{2 \pi}\left[\arctan \left(\frac{1}{C}\right)-\frac{C}{Y} \arctan \left(\frac{1}{Y}\right)\right]
$$

where

$$
A=a / b, C=c / b, Y=\sqrt{A^{2}+C^{2}}
$$



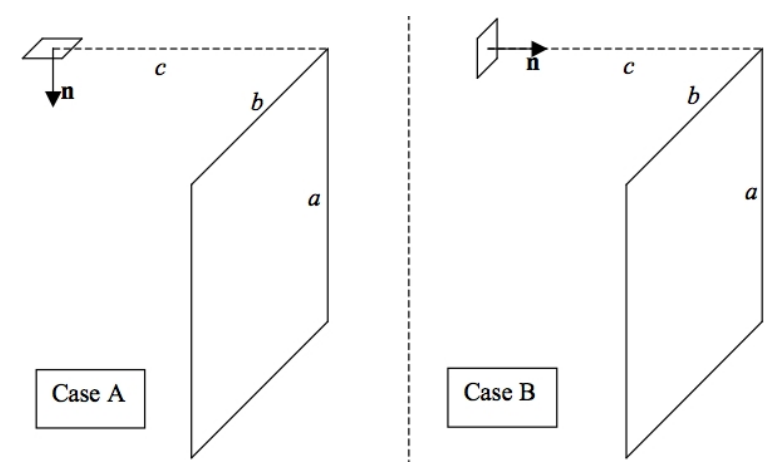

Figure 9. VIEW FACTOR CALCULATION SCHEMATIC AND INPUT PARAMETERS (ADAPTED FROM [10]).

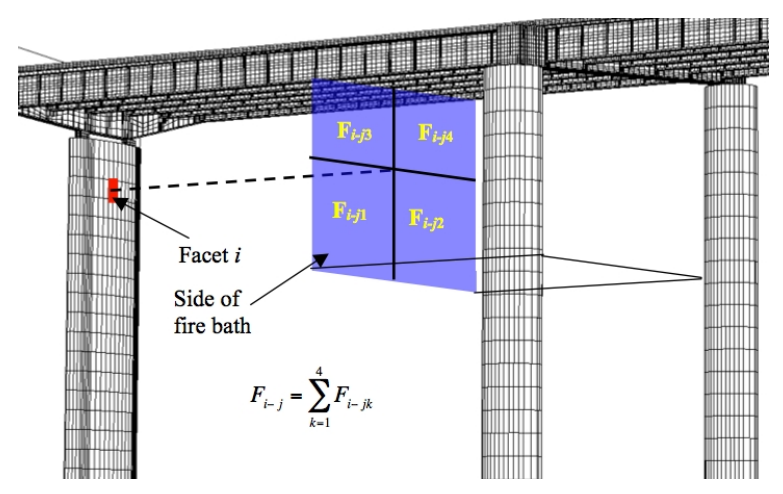

Figure 10. VIEW FACTOR CALCULATION FOR FACETS WITH SIDE OF FIRE BATH.

or where the differential surface is parallel to the finite rectangle aligned with rectangle's corner (Fig. 9, Case B) [10]:

$$
f_{\text {rad }}=\frac{1}{2 \pi}\left[A^{*} \arctan \left(\frac{B}{\sqrt{1+A^{2}}}\right)+B^{*} \arctan \left(\frac{A}{\sqrt{1+B^{2}}}\right)\right]
$$

where

$$
A=a / c, B=b / c, A^{*}=\frac{A}{\sqrt{1+A^{2}}}, B^{*}=\frac{B}{\sqrt{1+B^{2}}}
$$

All facets within the fire bath contain a view factor of 1.0. In general, either summation or subtraction of view factors is required to determine the net radiation exposure based on the normal drawn between the facet and the surface edge as shown in Fig.10. Also, in many instances a given finite element facet is exposed to two sides of the fire bath, so view factor summation is applied. We assumed a fixed fire temperature of $1200^{\circ} \mathrm{C}$ for our system to match known fire temperatures from Fig. 3 [2] .

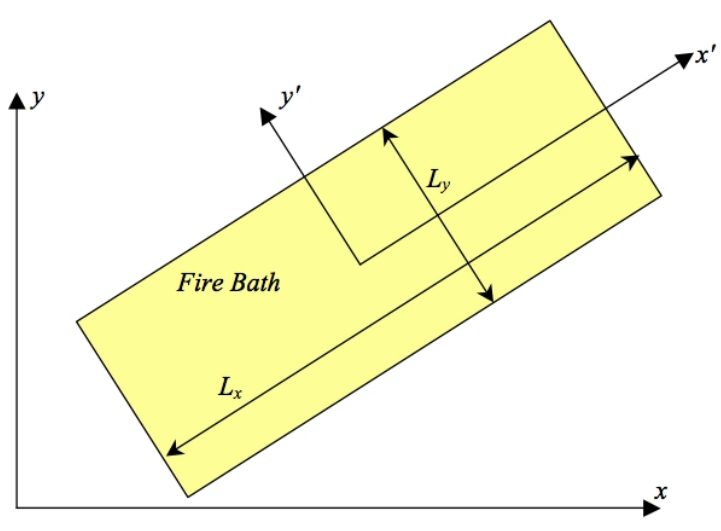

Figure 11. FIRE BATH ORIENTATION VECTORS FOR CONVECTIVE GAS TEMPERATURE CALCULATION.

Convective Transport. An accurate depiction of the heat transport between the hot gases escaping the fire bath that heats the surrounding surfaces requires a large-scale CFD fire simulation, but for simplicity we used a simple analytical model to compliment the fire bath radiative scheme. All gas within the fire bath contained a peak hot gas temperature of $T_{\text {gas }}^{*}=1.0$, where

$$
T_{g a s}^{*}=\left(\frac{T_{g a s}-T_{a m b}}{T_{g a s, \max }-T_{a m b}}\right)
$$

where $T_{\text {gas,max }}$ and $T_{a m b}$ are $500^{\circ} \mathrm{C}$ and $20^{\circ} \mathrm{C}$, respectively. Here, a simple exponential decay of the hot gas temperature is approximated for the heat transport,

$$
T_{\text {gas }}^{*}=\min \left(1, \exp \left[-\frac{\left(\left|x^{\prime}\right|-\frac{L_{x}}{2}\right)\left(\left|y^{\prime}\right|-\frac{L_{y}}{2}\right)}{L_{D}}\right]\right)
$$

where the vectors $L_{x}$ and $L_{y}$ are shown in Fig. 11. We chose a decay length $L_{D}=173 \mathrm{in}^{-1}(4.39 \mathrm{~m})$ such that $T_{\text {gas }}^{*}$ is reduced by a factor of 2 at a length of $10 \mathrm{ft}(3.05 \mathrm{~m})$ outside the fire bath.

Thermal Transport Notes. To complete the thermal model, the following were applied:

1. The initial temperature of all nodes in the mesh was $T_{a m b}$.

2. The convection relation for the top of the roadway to the ambient surroundings is $N u=0.15 R a^{1 / 3}$, which is valid for $10^{7}<R a<10^{11}$ [11]. Our system contains $R a \approx 10^{10}$. It was approximated that downward-facing facets experienced more heat transfer via radiation than convection, so convection is ignored for these facets. 
Table 1. SYSTEM THERMAL PROPERTIES OF MATERIALS.

\begin{tabular}{clll}
\hline Property & A709 Steel & Concrete & Ref. \\
\hline Density, $\mathrm{kg} / \mathrm{m}^{3}$ & 7861 & 2405 & {$[11]$} \\
Heat capacity, J/kg/K & 439.6 & 880 & {$[11]$} \\
Thermal conductivity, W/m/K & 62.3 & 1.0 & {$[11]$} \\
Surface emissivity & 0.7 & 0.94 & {$[10]$} \\
\hline
\end{tabular}

3. The convection relation for vertical systems is $N u=$ $0.10 R a^{1 / 3}$, which is valid for $R a \geq 10^{9}$ [11]. Convective transport for these facets is applied both to the fire and ambient surroundings.

4. Perfect thermal contact between the steel sleeves and the underlying concrete in the supporting columns was assumed.

5. Table 1 shows the thermal properties applied for the steel and concrete in the simulation. The results shown in this paper use fixed thermal properties for these materials since temperature-dependent values for A709 Steel are not available. However, subsequent calculations using the temperature-dependent properties of plain carbon steel from [11] show a sharper rise in the maximum nodal temperature in the system than when fixed properties were used.

In order to facilitate use of an explicit finite element code for the structural analysis, the simulated time was reduced from 3600 seconds to 3.6 seconds. Therefore, the heat capacity of the steel and concrete was increased by a factor of 1000 to maintain the left-hand side of the standard energy equation. Figure 12 shows that use of this approach provides equivalent temperature profiles within the fire bath within $0.001{ }^{\circ} \mathrm{C}$ when compared to a real-time model.

The initial approach to modeling the fire was to adjust the position and size of the fire bath based on the real-time video of the fire. The calculated structural temperature distribution at 60 minutes shown in Fig. 13 shows that the video places the fire predominantly under the MB18-19 section of the structure, despite the fact that the actual failure had first occurred in the adjoining MB19-20 section. This fact suggests that modeling the fire bath as uniformly heating may not be a valid assumption, although video of a substantial portion of the fire progression is not available. Nevertheless, we were able to get a reasonable agreement in collapse time and failure mode when the fire was positioned such that it straddled the MB19 beam as shown in Fig. 14, which shows that the general approach described here can give a first-order approximation of the failure modes and times.

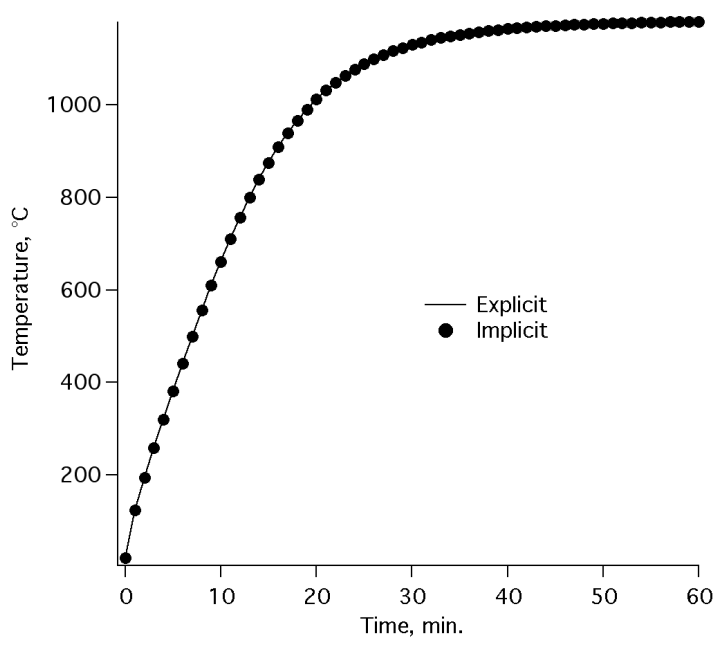

Figure 12. COMPARISON OF REPRESENTATIVE NODAL TEMPERATURE INSIDE FIRE BATH USING REAL-TIME AND ACCELERATEDTIME SIMULATIONS.

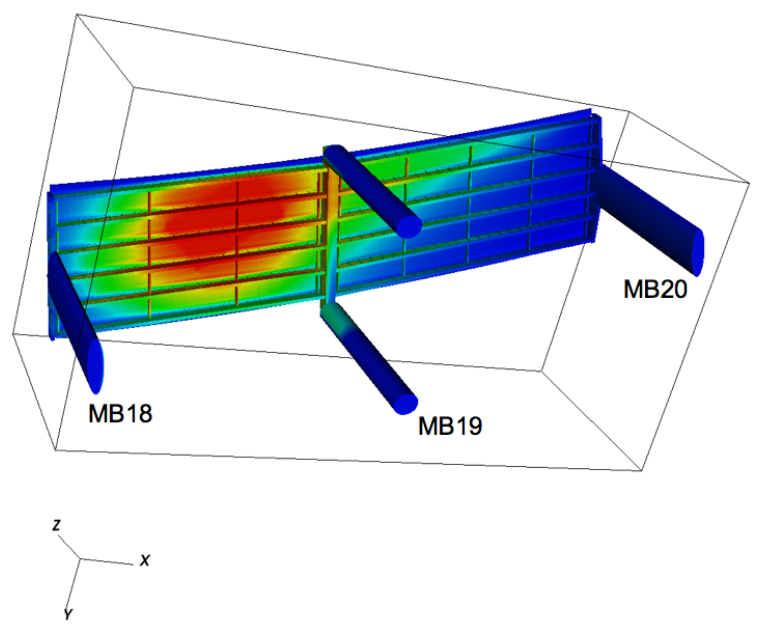

Figure 13. DETERMINATION OF FIRE BATH LOCATION AND SIZE BASED ON VIDEO SURVEILLANCE. MAXIMUM TEMPERATURE (SHOWN IN RED) IS $1200^{\circ} \mathrm{C}$.

\section{Thermal-Structural Analysis}

The final loosely coupled thermal/structural analysis was performed using Paradyn to allow for material failure. In order to perform this long time scale analysis in an explicit code, time was scaled by 1000 . In order to ensure that this approximation was reasonable, a Paradyn analysis (time scaled by 1000) and NIKE3D analysis (time scaled by 1 ) was performed for materials without element deletion and the two solutions were in 


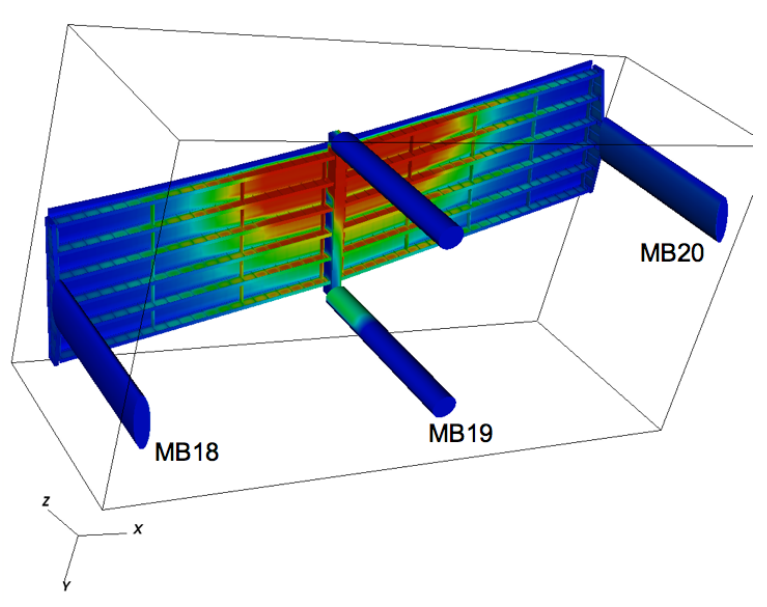

Figure 14. LOCATION AND SIZE OF FIRE BATH APPLIED IN SUCCESSFUL ANALYSIS. MAXIMUM TEMPERATURE (SHOWN IN RED) IS $1200^{\circ} \mathrm{C}$.

reasonable agreement (Fig. 15). The thermal load time scaling has the greatest influence on the structural behavior when there is a strong transient dynamic response, such as when a component fails. During these points in the analysis, the scaled thermal loads are applied at approximately the same time scale as the transient dynamic response. The increased thermal loading experienced during transient dynamic periods might alter the predicted failure mode, but is unlikely to shift the first-order failure time estimate. For the Paradyn failure analysis, it was assumed that element deletion would occur for the Grade 36 steel at an effective plastic strain of $10 \%$ and element deletion for the Grade 50 steel would occur at $15 \%$. Gravity was initialized prior to performing the thermal/structural analysis. We assumed that failure occurred when either a span sagged more than 15 feet 6 inches (the minimum clear distance between the roadways) or when a span failed completely from its connection.

Table 2 shows the collapse times and failure modes for models that use the fixed thermal properties from Table 1 or when the temperature-dependent thermal properties of plain carbon steel from [11] were used. The table shows that using fixed thermal properties overestimates the collapse time, while using temperature-dependent properties underestimates the collapse time. In addition, the failure modes differ between the two simulations and the EBMUD video, which suggests that more emphasis should be placed on the models of the connection points. Figure 16 shows the predicted failure at the end of the analysis for an assumed fire temperature of $1200^{\circ} \mathrm{C}$ and fixed thermal properties, and the maximum displacement of the girder nodes is shown in Fig. 17. Our two calculations show the large areas of uncertainty in our modeling method and choice of

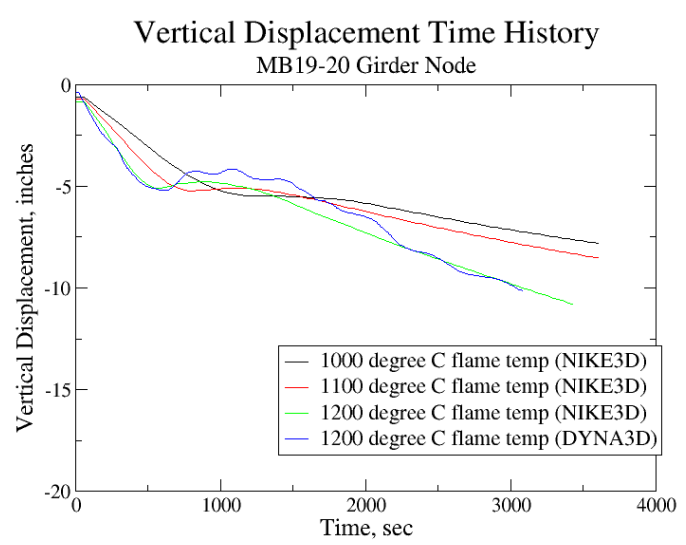

Figure 15. PARADYN AND NIKE3D DISPLACEMENT COMPARISON FOR MODELS WITHOUT ELEMENT DELETION.

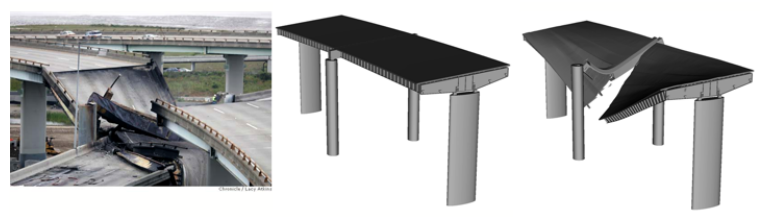

Figure 16. PARADYN FAILURE ANALYSIS COMPARED WITH PHOTO (PHOTO BY LACY ATKINS/SF CHRONICLE).

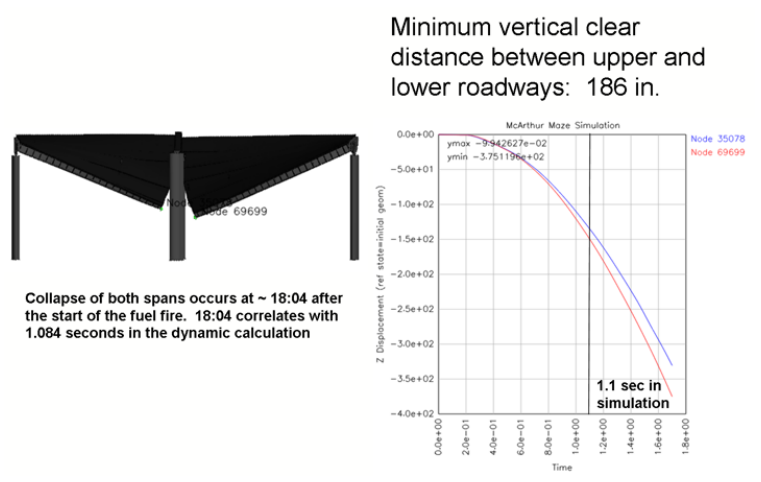

Figure 17. VERTICAL DISPLACEMENT TIME HISTORIES OF GIRDER NODES NEAR MB19 BOX BEAM.

modeling parameters, so our methods only provide a first-order prediction. However, we did find that consideration of the variation of the tangent modulus with respect to temperature was secondary to the overall thermal softening of the material.

The fully-coupled analysis is a work-in-progress using the implicit, parallel, multi-mechanics Diablo code under development at LLNL. The solution technique currently implemented in Diablo alternates solution of the thermal and stress mechanics governing equations to produce separate updates for the temper- 
Table 2. SPAN COLLAPSE TIMES AND FAILURE MODES.

\begin{tabular}{ccc}
\hline System & $\begin{array}{c}\text { North (MB18-19) } \\
\text { Span Failure Time }\end{array}$ & $\begin{array}{c}\text { South (MB19-20) } \\
\text { Span Failure Time }\end{array}$ \\
\hline EBMUD Video & $18: 04 \dagger$ & $16: 42 \dagger$ \\
Fixed $k, c_{p}$ (Table 1) & $21: 30 \ddagger$ & $20: 15 \ddagger$ \\
$k(T), c_{p}(T)[11]$ & $16: 15 \ddagger$ & $10: 00 \dagger$ \\
\hline$\dagger$ Nodal failure along entire span \\
\$Maximum sag distance along span exceeded clearance limits \\
\hline
\end{tabular}

ature and displacement fields. The governing thermal equations are solved to determine the current nodal temperatures, which are passed to the stress mechanics step to update temperaturedependent material properties. The governing stress equations are then solved to determine the current displacements; the current configuration, contact pressures, and dissipative work (from contact and material models) are then passed back to the thermal mechanics step to update thermal transport properties. The loop through the thermal and stress mechanics solutions is repeated a specified number of times for each time step. The preliminary Diablo analysis results indicate larger girder displacements near bent MB19 than at the corresponding time in the Paradyn analysis. This behavior is consistent with structural deformations affecting how thermal loads are propagated into the system; however, numerical difficulties have prevented the analysis from preceding far enough to estimate a structural failure time from the fully-coupled analysis.

\section{CONCLUSIONS}

The thermal analysis approach used here is obviously very approximate and can potentially be improved through application of a fire dynamics code such as Fuego [12] from Sandia National Laboratories or various codes from the National Institutes of Standards and Technology Building and Fire Research Laboratory [13]. However, the use of these fire simulation codes is hampered due to lack of knowledge regarding the wind patterns at the time of the fire. The predictions of the Maze connector collapse show that the approach outlined in this paper provides a simple means to approximate failure times via thermal and structural finite element analysis. The approximate time to failure could be used as a first-order predictive capability to assess the thermal vulnerability of structural systems. Additional accuracy on the failure mechanism can be gained by providing more details on the temperature-dependent thermal properties and connections between the girders and the box beam.

\section{ACKNOWLEDGMENT}

Information and advice by Prof. Abolhassan AstanehAsl at U. C. Berkeley is greatly appreciated. This work performed under the auspices of the U.S. Department of Energy by Lawrence Livermore National Laboratory under Contract DEAC52-07NA27344.

\section{REFERENCES}

[1] Bulwa, D., and Fimrite, P., 2007. Tanker Fire Destroys Part of MacArthur Maze, 2 Freeways Closed Near Bay Bridge. San Francisco Chronicle newspaper, April 29.

[2] Buyukozturk, O., and Ulm, F., eds., 2002. Materials and Structures, $1^{\text {st }}$ ed. The Towers Lost and Beyond. MIT, Cambridge, MA, Chap. 6, pp. 83-106. edited by E. Kausel.

[3] Maker, B. N., Hallquist, J. O., and Ferencz, R. M., 1995. NIKE3D - a Nonlinear, Implicit, Three-Dimensional Finite Element Code for Solid and Structural Mechanics User's Manual. Tech. rep., Lawrence Livermore National Laboratory, Livermore, CA. UCRL-MA-105268-REV-1.

[4] Whirley, R. G., and Engelmann, B. E., 1993. DYNA3D, a Nonlinear, Explicit, Three-Dimensional Finite Element Code for Solid and Structural Mechanics - User Manual. Tech. rep., Lawrence Livermore National Laboratory, Livermore, CA. UCRL-MA-107254-REV-1.

[5] Hoover, C. G., DeGroot, A. J., and Sherwood, R. J., 2000. Paradyn, a Parallel Nonlinear, Explicit, Three-Dimensional Finite Element Code for Solid and Structural Mechanics User Manual. Tech. rep., Lawrence Livermore National Laboratory, Livermore, CA. UCRL-MA-140943.

[6] Wemhoff, A. P., Havstad, M. A., and Shapiro, A. B., 2007. TOPAZ3D Users Manual - A 3-dimensional Finite Element Heat Transfer Code. Tech. rep., Lawrence Livermore National Laboratory, Livermore, CA, September. UCRL-SM234673.

[7] Parsons, I. D., Solberg, J. M., Ferencz, R. M., Havstad, M. A., and Hodge, N. E., 2007. Diablo User Manual. Tech. rep., Lawrence Livermore National Laboratory, Livermore, CA. UCRL-SM-234927.

[8] Telford, T., 1993. Comite Euro-International du Beton, Federation Internationale de la Precontrainte, CEB-FIP Model Code 1990.

[9] Takagi, J., and Deierlein, G., 2007. "Strength Design Criteria for Steel Members at Elevated Temperatures". J .Constructional Steel Research, 63, pp. 1036-1050.

[10] Siegel, R., and Howell, J. R., 1992. Thermal Radiation Heat Transfer, 3 ed. Taylor and Francis, Philadelphia, PA.

[11] Incropera, F. P., and DeWitt, D. P., 1996. Fundamentals of Heat and Mass Transfer, 4 ed. Wiley, New York.

[12] Sandia, 2007. Sierra/Fuego Users Manual 2.5. Tech. rep., Sandia National Laboratories, Albuquerque, NM, June. SAND2006-6084P. 
[13] http://www.bfrl.nist.gov/info/software.html. 